\section{Continental Mathematics}

T he scientific contributions of Christiaan Huygens (162995) were many and varied. He expounded the wave theory of light, hypothesised that Saturn has a ring, wrote the first formal probability text, and invented the pendulum clock whose operation was based on properties of the cycloid.

Although Newton could justly claim priority for the calculus, Gottfried Wilhelm Leibniz (1646-1716), who developed it independently, was the first to publish it; his notations, including $d y / d x$ and the integral sign, were more versatile than Newton's and are still used today. Leibniz's calculus differed from Newton's, being based on sums and differences rather than velocity and motion.
The Bernoulli family included several distinguished Swiss mathematicians. In his Ars Conjectandi [Art of Conjecturing], Jakob Bernoulli (1654-1705) presented the law of large numbers, that if an experiment is performed often, there is a high probability that the outcome will be as expected. With his brother Johann he was among the first to develop Leibniz's calculus, applying it to the study of curves such as the catenary and the cycloid.

The Comte de Buffon (1707-88) is best remembered for his 'needle experiment' which can be used to estimate $\pi$ experimentally: if we throw $N$ needles of length $L$ randomly onto a grid of parallel lines at distance $d$ apart, then the expected number of needles crossing a line is $2 N L / \pi d$

Jean le Rond d'Alembert (1717-83) was a leading Enlightenment figure who obtained the wave equation that describes the motion of a vibrating string, tried to formalize the idea of a limit, and stated the ratio test for the convergence of an infinite series. He wrote most of the mathematical articles for Denis Diderot's Encyclopédie, which attempted to classify the knowledge of the time.
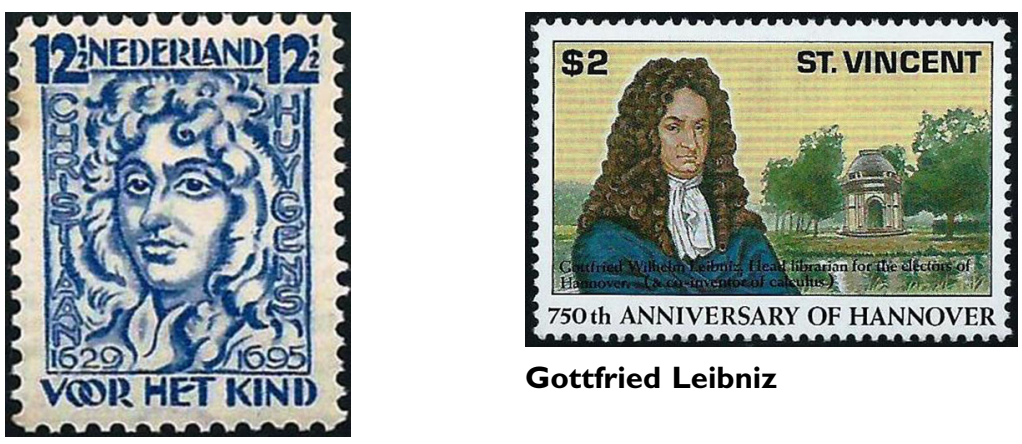

Gottfried Leibniz

\section{Christiaan Huygens}

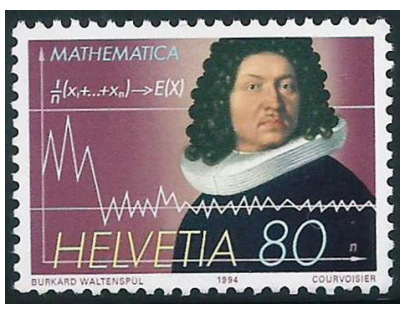

Jakob Bernoulli

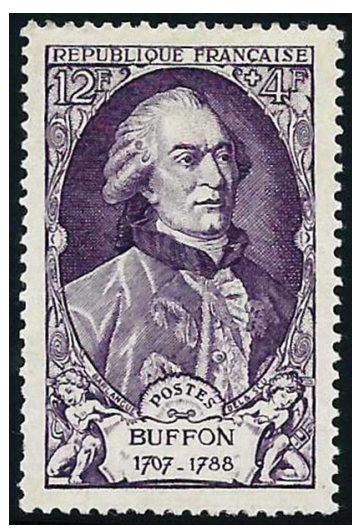

Comte de Buffon

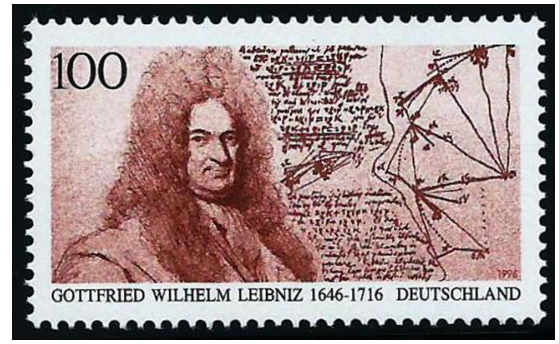

Leibniz and diagram

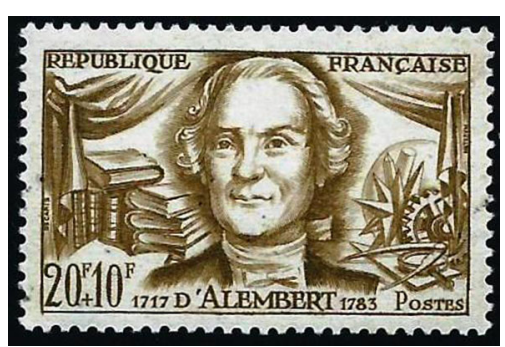

Jean d'Alembert

> Column editor's address: Robin Wilson, Mathematical Institute,

Andrew Wiles Building, University of Oxford, UK

e-mail: r.j.wilson@open.ac.uk 